\title{
Correction to: Recurrence with pagetoid spread arising 17 years after surgery for intramucosal rectal cancer: a case report
}

Taichi Matsubara, Yuta Kasagi, Kippei Ogaki, Yu Nakaji, Ryota Nakanishi, Yuichiro Nakashima, Masahiko Sugiyama, Hideto Sonoda, Hiroshi Saeki, Eiji Oki and Yoshihiko Maehara

\section{Correction}

After publication of the original article [1] the authors noted that the following errors had occurred:

Figure 1c: The vertical line in Figure 1c is misaligned, and partly overlaps ' $12 \mathrm{y} \sim$ '. The time points in the clinical course are also incorrect and have been updated in this Correction (Revised Fig. 1). In the original article the time points were labelled as $1 \mathrm{y} \mathrm{m}$ (amended to $1 \mathrm{y}$ ), $2 \mathrm{y} \mathrm{m}$ (amended to 2y), $16 \mathrm{y} \mathrm{m}$ (amended to $16 \mathrm{y} 4 \mathrm{~m}$ ), $16 \mathrm{y} \mathrm{m}$ (amended to $16 \mathrm{y} 7 \mathrm{~m}$ ) and $17 \mathrm{y} \mathrm{m}$ (amended to 17 y $3 \mathrm{~m}$ ).

Figure 2c: The items for immunostaining (CK7, CK20, CEA, and GCDFP15) are misaligned in Figure 2c and have been updated in this Correction (Revised Fig. 2).

The errors do not affect the Conclusions of the original article.

Received: 3 January 2018 Accepted: 3 January 2018

Published online: 25 January 2018

\section{Reference}

1. Matsubara T, Kasagi Y, Ogaki K, Nakaji Y, Nakanishi R, Nakashima Y, Sugiyama

M, Sonoda H, Saeki H, Oki E, Maehara Y. Recurrence with pagetoid spread

arising 17 years after surgery for intramucosal rectal cancer: a case report.

Surgical Case Reports. 2017;3:85. https://doi.org/10.1186/s40792-017-0356-5.

\footnotetext{
* Correspondence: okieiji@surg2.med.kyushu-u.ac.jp

Department of Surgery and Science, Graduate School of Medical Sciences, Kyushu University, Fukuoka 812-8582, Japan
} 
a

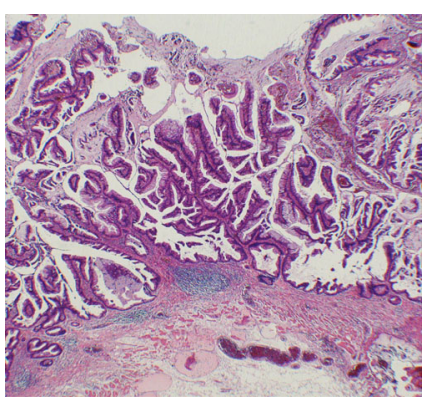

C

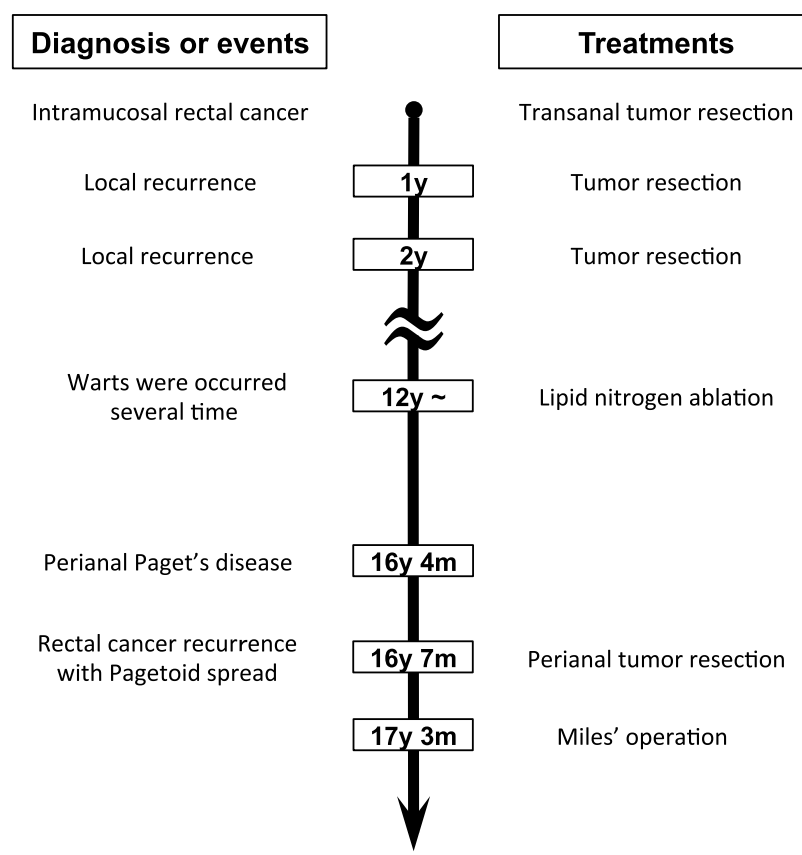

b

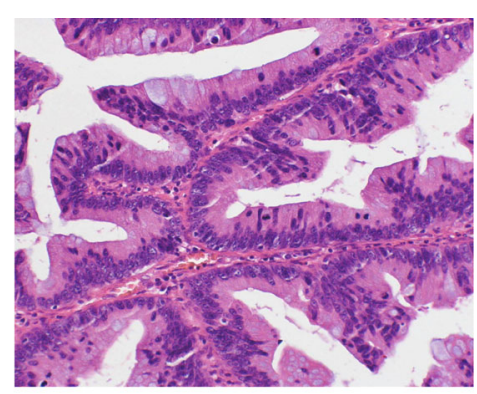

Treatments 

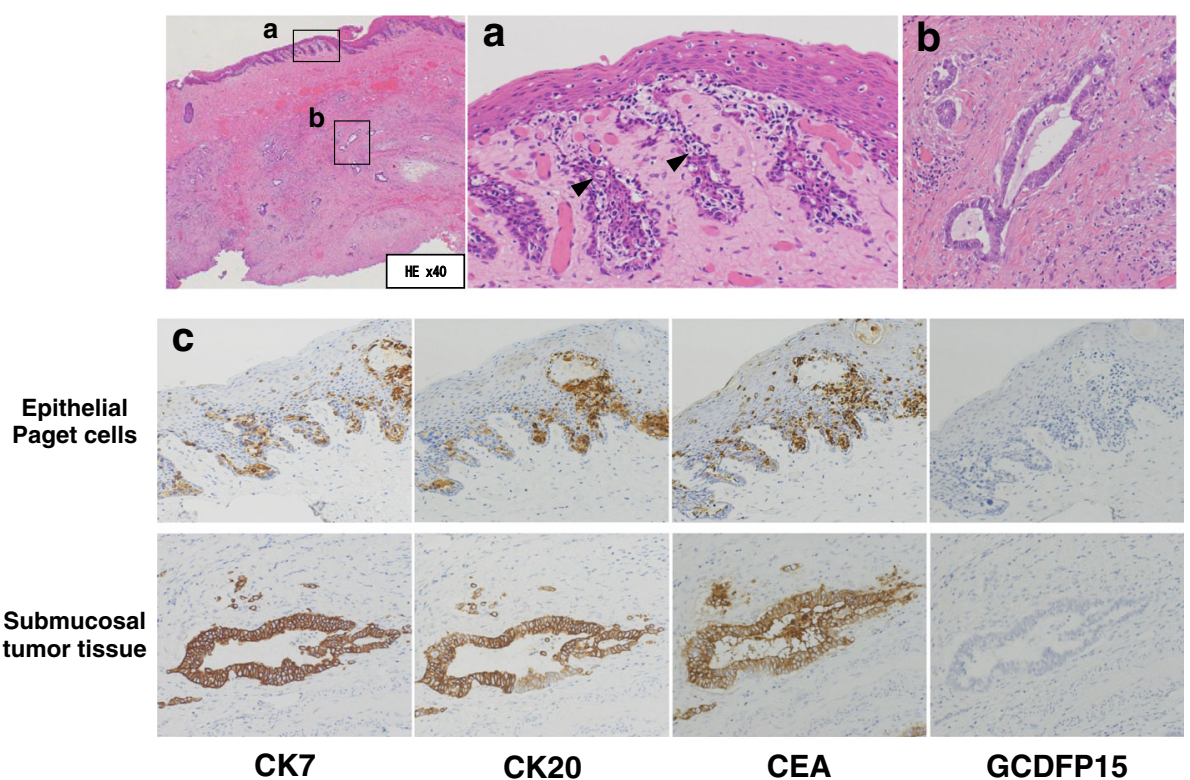

Fig. 2 Paget cells were scattered in squamous epithelium (arrow head) (a) (HE $\times 200)$. Adenocarcinoma tissue was observed in the submucosa (b) $(H E, \times 200)$. Immunohistochemical staining revealed that CK7, CK20, and CEA expression was positive in epithelial Paget cells and submucosal adenocarcinoma tissues. However, GCDFP-15 activity was not detected in any lesions (c) $(\times 200)$ 